heat received in twenty-four hours from the sun on the summer solstice is not greatest at latitude $231^{\circ}$, where the sun is vertical, but has two maxima farther north, - one at $43^{\circ}$; the other and greater at the pole, with a faint minimum at $66^{\circ}$; because the sunshine at the pole through twenty-four hours, at a constant altitude of $23 \frac{1}{2}^{\circ}$, is greater than the sunshine in the twelve-hour day at the tropic, with the sun vertical only at noon. But this gives a very erroneous idea of the temperatures at these latitudes. Now, on the assumption that two or three tenths of a vertical ray are absorbed by the atmosphere, Angot finds the maximum of heat received at the bottom of the atmosphere on the solstice has its maximum at $35^{\circ}$; farther north, the heat received diminishes continuously to the pole, rapidly at first, then slowly beyond the polar circle; and this is fairly conformable to the distribution of temperature. An interesting calculation shows, that, on account of our less distance from the sun in December than in June, the latitude circle about $22^{\circ}$ north, and not the equator, receives the same amount of heat on the two solstices : the equator, therefore, belongs in this respect to the southern hemisphere. The memoir is illustrated by an instructive series of curves showing the distribution of heat over the earth at numerous dates.

W. M. D.

\section{SODA AND POTASH IN THE FAR WEST.}

IN view of the large quantities of soda and potash in various forms that are imported into this country, it is surprising that the abundant supplies of these alkalies within our own borders are not more extensively utilized.

It is probably known to all American geologists that there are extensive deposits of the chloride, sulphate, and carbonate of soda at many points in the arid regions of the far west, which may be had for the trouble of gathering. These deposits occur in the desiccated beds of ancient lakes in Nevada, Arizona, western Utah, and portions of California and New Mexico. There are certain lakes, also, which are valuable brines.

In the basins where evaporation has been nearly or quite complete, the alkaline salts occur either at the surface, when they appear like fields of snow frequently many square miles in extent, or they may be concealed beneath the layers of fine mud known as playa deposits. Again, large areas in Nevada and Arizona are white with alkaline salts that have been brought to the surface in solution, and deposited when the waters evaporated. These efflorescences are frequently rich in sodium carbonate, sulphate, and borate, and have been utilized to a limited extent at a few localities.
The lakes of the far west which are likely to become of commercial value on account of the alkaline salts they contain are Great Salt Lake, Utah; the Soda Lakes, near Ragtown, Nevada; Mono and Owen's lakes, California ; and Summer and Abert lakes, in Oregon. All of these are without outlet, and owe their high percentage of mineral matter to the concentration by evaporation of the waters of streams and springs with which they are supplied. Their chemical composition is shown in the following table :-

\begin{tabular}{|c|c|c|c|c|c|}
\hline CONSTITUENTS. & 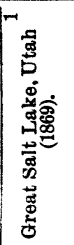 & 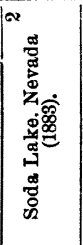 & 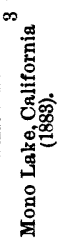 & 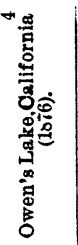 & 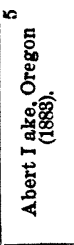 \\
\hline Sodium (Na). & 49.690 & 40.919 & 18.100 & 21.650 & 2.773 \\
\hline Potassium (K).. & 2.407 & $2.35 \%$ & 1.111 & 2.751 & $10.63 i$ \\
\hline Calcium (Ca) ... & 0.255 & $\cdots$ & 0.278 & trace & \\
\hline Magnesium $(\mathbf{M g})$. & 3.780 & 0.245 & 0.125 & trace & $0 . \mathrm{CO}$ \\
\hline Lithium (Li)............... & trace & & . & trace & \\
\hline Chlorine (Cl)........ & 83.946 & 40.851 & 11.610 & 13.440 & 8.220 \\
\hline Bromine (Br) & trace & $\ldots \ldots$ & ........ & 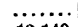 & $\cdots \ldots$ \\
\hline Carbonic acid (CO & $\cdots$ & 16.854 & 11.465 & 18.140 & 4.547 \\
\hline Sulphuric " $\left(\mathrm{SO}_{4}\right) \ldots \ldots \ldots$ & 9.858 & 11.857 & 6.520 & 9.362 & $0.49 ?$ \\
\hline Phosphoric " $\left(\mathrm{HPO}_{4}\right) \ldots \ldots$. & ........ & $\cdots$ & (......... & trace & $\cdots \cdots \cdots$ \\
\hline$"\left(\mathrm{NO}_{3}\right) \ldots$ & ........ & & $\ldots \ldots$ & trace & $\cdots \cdots \cdots$ \\
\hline$"\left(\mathrm{~B}_{4} \mathrm{O}_{7}\right) \ldots \ldots$ & trace & 0.286 & 0.153 & trace & $\cdots \ldots$ \\
\hline Silica $\left(\mathrm{SiO}_{2}\right) \ldots \ldots \ldots \ldots \ldots \ldots$ & 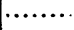 & 0.278 & 0.268 & 0.164 & 0.064 \\
\hline Alumina $\left(\mathrm{Al}_{2} \mathrm{O}_{3}\right)$ & $\cdots$ & …… & $\ldots \ldots$ & trace & ・. \\
\hline Total parts per thousand & 149.936 & 113.647 & 49.630 & 60.507 & 26.740 \\
\hline
\end{tabular}

1 Analysis by Prof. O. D. Allen, U. S. geol. explor. of the 40th par., vol. ii. p. 435.

2 Analysis by Dr. T. M. Chatard, Bull. No. 9, U. S. geol. surv., p. 25. 2 Abid., p. 26.

4 Analysis by Dr. Oscar Loew, Ann. rep. chief of eng., U.S.A., 1876, p. 190 .

5 Analysis by Dr. F. W. Taylor, Fourth ann. rep., U. S. geol. surv., 1882-83, p. 454 .

It is safe to predict that Great Salt Lake will not only be of great value in the near future on account of the immense quantities of common salt it is capable of producing, but also for the sodium sulphate it contains. When the temperature of the lake-water is reduced to $20^{\circ} \mathrm{F}$, , the separation of sodium sulphate takes place as a flocculent precipitate, which increases in quantity with decrease of temperature. This should suggest to manufacturers a method of obtaining the salt in a pure state and on a large scale. When the temperature of Great Salt Lake is lowered on the approach of winter, its waters become opalescent, owing to the precipitation of sodium sulphate in an extremely finely divided state. During the winter months the temperature of the air in the region of the lake sometimes falls to $20^{\circ}$ or more below $0^{\circ} \mathrm{F}$., and at such times the separation of sodium sulphate takes place on an immense scale, and it is thrown up on the shore in thousands 
of tons. The amount that could be gathered at such times is practically unlimited. As railroads now touch the shore of the lake, the problem of supplying this salt to manufacturers is simplified.

The Soda Lakes, situated on the Carson desert, Nevada, about fourteen miles east of Wadsworth, have already been utilized as a source of sodium carbonate, which is being shipped to San Francisco. These lakes occupy the craters of extinct volcanoes, and the mineral matter they contain has been derived mainly from the leaching of the lapilli and lacustral deposits surrounding them.

Mono and Owen's lakes are now quite accessible by rail, and are capable of furnishing immense quantities of sodium sulphate and carbonate. From data obtained during a recent survey of Mono Lake, it has been estimated that it contains,

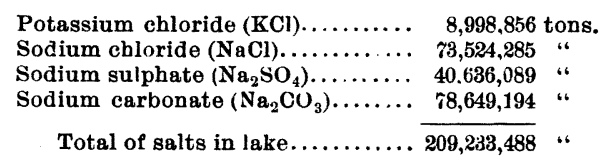

It has been estimated by Dr. Oscar Loew that Owen's Lake contains about twenty-two million tons of sodium carbonate, and a little less than one-third of this amount of sodium sulphate.

Summer and Abert lakes, situated in southern Oregon, are remote from railways, but are extremely valuable brines on account of the potash salts they contain. These lakes occupy depressions in the bed of an ancient lake of large size, now nearly desiccated, and are very similar in character. Abert Lake alone has been analyzed, but it is probable that its companion has nearly an identical composition. Abert Lake is about fifteen miles long by five miles broad, and has an average depth (varying with the seasons) of approximately ten feet. Summer Lake is perhaps a third larger, and is also shallow; but its average depth is unknown. The percentage of potassium salts in Abert Lake is greater than in any other lake the composition of which has been published, amounting to five-sevenths of the total of solids in solution.

With these abundant resources at hand, the alkali industry of the far west unquestionably has a great future ; and it is to be hoped that it will soon receive the attention that its importance demands.

I. C. Russell.

\section{CHOLERA MORTALITY IN EUROPE DUR- ING 1885.}

Cholera as an epidemic has now for some time almost entirely disappeared from southern Europe, and hence the following results of the serious outbreak of the past year, from the Lancet of Dec. 26, will be of interest : From the mainland no further record of cholera is forthcoming; but in the Christina Islands to the south, near the mouth of the Guadiana River, recurrences of the disease are still said to take place. The actual number of deaths recorded in the provinces and cities named is less than that which really occurred; for the official lists were not published with sufficient regularity to insure accurate records day by day, and outbreaks in some localities were never announced at all. The following is the list of places attacked, with their respective cholera mortalities; the capitals of the several provinces being, except where otherwise noted, included for statistical purposes within their provinces :-

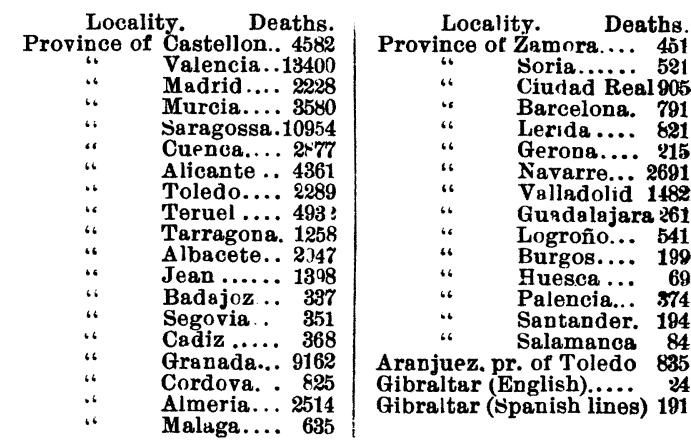

In France the disease was all but limited to Marseilles and Toulon, and to scattered cases in the south, until November, when an outbreak occurred in Brittany, Brest and its immediate neighborhood being affected. The total cholera deaths at Marseilles were just short of 1,000, and at Toulon just short of 200 . The number at Brest has not been made known. In Italy only scattered cases occurred at several places on the mainland; but in the city and province of Palermo, in the island of Sicily, a considerable epidemic occurred, the total mortality there reaching at least 2,430. There was also a rumor of cases as late as the present month in the province of Venice.

\section{BURMAH, PRESENT AND FUTURE.}

Mr. Holt HaLlett, in a recent address before the London Society of arts, on 'Burmah,' said : In these days, with foreign competition getting keener every day, and hostile tariffs not only shutting the Europeon markets against us, but in a lesser degree American and English colonies also, with the race for fresh colonies and new markets among European powers, it is of importance that we should avail ourselves of our present opportunity for an inland connection and 